University of Wollongong

Research Online

Faculty of Engineering and Information

Faculty of Engineering and Information

Sciences - Papers: Part A

Sciences

$1-1-2012$

\title{
Thermodynamic analysis of a high-yield biochemical process for biofuel production
}

M Imroz Sohel

University of Wollongong, msohel@uow.edu.au

Michael W. Jack

Scion

Follow this and additional works at: https://ro.uow.edu.au/eispapers

Part of the Engineering Commons, and the Science and Technology Studies Commons

Research Online is the open access institutional repository for the University of Wollongong. For further information contact the UOW Library: research-pubs@uow.edu.au 


\title{
Thermodynamic analysis of a high-yield biochemical process for biofuel production
}

\begin{abstract}
This paper presents a thermodynamic analysis of a high-yield biochemical process for biofuel production from lignocelluosic biomass based on a previously proposed process. Unlike the standard biochemical process, which ferments sugar intermediates to ethanol, the process under consideration converts sugars to acetic acid which is esterified and hydrogenated to produce ethanol. This process has a significantly higher yield and produces no carbon dioxide. However, we find that the thermodynamic efficiency of the process is not increased in proportion to the yield gain. An additional survey of various biofuel production processes showed no direct correlation between yield and thermodynamic efficiency. This survey and the detailed thermodynamic analyses lead us to conclude that yield alone is an unreliable performance metric for biofuel technologies.
\end{abstract}

\section{Keywords}

thermodynamic, production, analysis, high, yield, biochemical, process, biofuel

Disciplines

Engineering | Science and Technology Studies

\section{Publication Details}

Sohel, M. Imroz. \& Jack, M. W. (2012). Thermodynamic analysis of a high-yield biochemical process for biofuel production. Bioresource Technology, 124 406-412. 


\title{
Thermodynamic analysis of a high-yield biochemical process for biofuel production
}

\author{
M. Imroz Sohel*, Michael W. Jack \\ Scion, 49 Sala St., Private Bag 3020, Rotorua 3020, New Zealand
}

\section{H I G H L I G H T S}

- The HYBC has similar order of thermodynamic efficiency to other processes.

- Efficiency can be increased by improving the heat and power production process.

- The hydrogenation process is inherently inefficient.

- No direct correlation between yield and thermodynamic efficiency was found.

\section{A R T I C L E I N F O}

\section{Article history:}

Received 7 June 2012

Received in revised form 13 August 2012

Accepted 14 August 2012

Available online 24 August 2012

\section{Keywords:}

Bioenergy

Exergy analysis

Lignocellulosic biomass

High-yield process

\begin{abstract}
A B S T R A C T
This paper presents a thermodynamic analysis of a high-yield biochemical process for biofuel production from lignocelluosic biomass based on a previously proposed process. Unlike the standard biochemical process, which ferments sugar intermediates to ethanol, the process under consideration converts sugars to acetic acid which is esterified and hydrogenated to produce ethanol. This process has a significantly higher yield and produces no carbon dioxide. However, we find that the thermodynamic efficiency of the process is not increased in proportion to the yield gain. An additional survey of various biofuel production processes showed no direct correlation between yield and thermodynamic efficiency. This survey and the detailed thermodynamic analyses lead us to conclude that yield alone is an unreliable performance metric for biofuel technologies.
\end{abstract}

(c) 2012 Elsevier Ltd. All rights reserved.

\section{Introduction}

A key challenge for biofuel production systems is to develop efficient conversion technologies which are able to compete economically with fossil fuels. One of the most common strategies for improving the effectiveness of biofuel production is to focus on increasing yield. In biochemical approaches to lignocellulosic biofuel production this can be achieved by increasing biofuel yield from the cellulose and hemicellulose fraction of lignocellulosic biomass (Ragauskas et al., 2006). A number of processes have been proposed that consist of a novel combination of fermentation and chemical conversion steps. These processes can significantly increase the yield of biofuel from carbohydrates compared to current biochemical routes and therefore potentially represent improved processes (Granda et al., 2009; Holtzapple et al., 1999; Lavarack et al., 2007; Verser and Eggman, 2003). On the other hand, biofuel production is fundamentally an energy conversion process and therefore energy efficiency, or more precisely thermodynamic efficiency, is also a critical factor for biofuel production. Thermodynamic analysis, based on the first and second laws of

\footnotetext{
* Corresponding author. Tel.: +64 7 3435730; fax: +64 73435375.

E-mail address: mohammed.sohel@scionresearch.com (M.I. Sohel).
}

thermodynamics has been applied previously to biofuel production (Prins et al., 2005; Sohel and Jack, 2011) and has been shown to be a powerful tool in comparing different technologies and identifying inefficiencies. It is therefore important to apply thermodynamic analysis to high-yield processes to investigate the largest inefficiencies as well as to investigate any correlation between thermodynamic efficiency and yield.

In the conventional biochemical process (Huber et al., 2006), yeast fermentation is an important component step where $1 \mathrm{~mol}$ glucose is converted into $2 \mathrm{~mol}$ ethanol and $2 \mathrm{~mol}$ of carbon dioxide:

$$
\mathrm{C}_{6} \mathrm{H}_{12} \mathrm{O}_{6} \rightarrow 2 \mathrm{C}_{2} \mathrm{H}_{5} \mathrm{OH}+2 \mathrm{CO}_{2}
$$

This means that a maximum of $92 \mathrm{~kg}$ of ethanol can be produced from $180 \mathrm{~kg}$ of glucose, i.e., for the conventional biochemical process the theoretical yield is about $52 \%(\mathrm{w} / \mathrm{w})$.

Lavarack and colleagues (Lavarack et al., 2007) have discussed a high-yield biochemical process, with the potential to utilise benefits of both biochemical and thermochemical pathways to biofuel production (Sohel and Jack, 2011). Lavarack and colleagues (2007) based their work on a previously patented work (Verser and Eggman, 2003). This process utilises bacteria to convert fermentable sugars to acetic acid. The acetic acid is then esterified 


\section{Nomenclature}

$E_{\mathrm{X}}$

I

$x$

Y

\section{Subscript}

ch

el

ph

prd

wstprd

Greek letters

$\eta$

$\alpha$

$\beta$ exergy (MW)

irreversible exergy loss (MW)

normalised yield $(-)$

yield $(-)$

chemical

electrical

physical

product

waste

efficiency $(-)$

ratio of mass of cellulose and hemicellulose to biomass (-)

ratio of mass of biofuel to mass of cellulose and hemicellulose $(-)$ and hydrogenated to produce ethanol. One of the possible options in this process is to gasify the lignin to provide the hydrogen for the hydrogenation process. The overall chemical reaction of this process (Lavarack et al., 2007) can be summarised by

$\mathrm{C}_{6} \mathrm{H}_{12} \mathrm{O}_{6}+6 \mathrm{H}_{2} \rightarrow 3 \mathrm{C}_{2} \mathrm{H}_{5} \mathrm{OH}+3 \mathrm{H}_{2} \mathrm{O}$

Here, $1 \mathrm{~mol}$ of glucose reacts with $6 \mathrm{~mol}$ of hydrogen to produce $3 \mathrm{~mol}$ of ethanol. This means that theoretically about $77 \%$ glucose sugar $(\mathrm{w} / \mathrm{w})$ can be converted to ethanol in the process. The process presented by Verser and Eggman (2003) can therefore achieve a $50 \%$ theoretical gain in yield of ethanol from sugar compared to the well known biochemical route (Wooley et al., 1999).

In this paper we present a model of a high-yield biochemical process (HYBC) for bioethanol production from lignocellulosic biomass, which is loosely based on Lavarack et al. (2007). We apply thermodynamic (exergy) analysis (Szargut et al., 1988) to the HYBC to determine the overall thermodynamic efficiency of the process and to identify major areas of inefficiency. We also discuss potential approaches to improve the efficiency of HYBC process. Finally, the yield and efficiency of the HYBC are compared with standard biochemical and thermochemical processes and we speculate on the general significance of these results for biofuel production processes.

\section{Materials and methods}

\subsection{A high-yield biochemical process for bioethanol production}

The HYBC considered here is loosely based on Lavarack et al. (2007) process. After an initial pretreatment stage that produces fermentable sugars from lignocellulose, there are three distinct process steps to the HYBC process: (i) Glucose sugars are converted to acetic acid in either a one step or a two step bacterial fermentation process. Lactic acid is produced as an intermediary. (ii) The acetic acid produced from fermentation is reacted with ethanol to form ethyl acetate. (iii) The ethyl acetate is split into two ethanol molecules by the hydrogenation process. About half of the ethanol formed in the hydrogenation process is recycled to the esterification process and the balance is sent forward as product. All the conversion information in steps (i)-(iii) are taken from Verser and Eggman (2003).

The required hydrogen for these processes can be supplied from a number of sources, including: steam reforming of natural gas, gasifying biomass, or electrolysis. Lavarack et al. (2007) suggested that natural gas or coal-seam gas are the most appropriate sources for an ethanol plant situated in north Queensland, Australia. In our model we have used natural gas to supply hydrogen as a base case. However, we have also analysed a scenario where the required hydrogen is met by gasifying the lignin-rich residue.

To construct a process model of the HYBC process, we have used the National Renewable Energy Laboratory (NREL) process model (Wooley et al., 1999) for mass balance information for the pretreatment stage up to sugar syrup production. The data presented by Piccolo and Bezzo (2009) has been used for heat requirements in this pretreatment stage. The remaining process operations are very similar to those presented by Verser and Eggman (2003).

Fig. 1 presents a simplified process flow diagram of the HYBC process. There are six major process steps involved: feed handling, pretreatment and detoxification, saccharification, fermentation, esterification, and hydrogenation. Other important processes include heat and power production and steam reforming to produce hydrogen. We have considered a process capacity of 160 metric

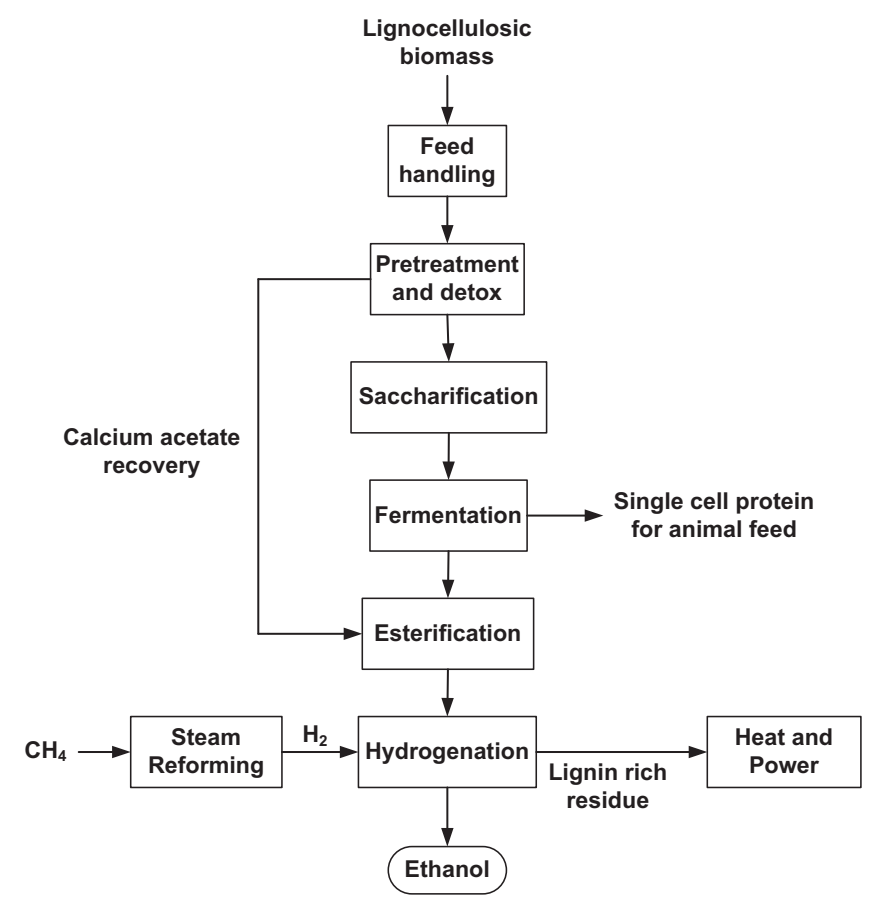

Fig. 1. Simplified schematic process flow for the HYBC process for ethanol production from wood chip where hydrogen is produced from natural gas. 
Table 1

Simplified mass flow $(\mathrm{kg} / \mathrm{s})$ of bioethanol production via the HYBC process.

\begin{tabular}{|c|c|c|c|c|c|c|c|c|c|c|c|c|c|c|c|c|}
\hline \multirow[t]{2}{*}{$\begin{array}{l}\text { Chemical } \\
\text { component }\end{array}$} & \multicolumn{2}{|c|}{ Feed handling } & \multicolumn{2}{|c|}{$\begin{array}{l}\text { Pretreatment \& } \\
\text { detoxification }\end{array}$} & \multicolumn{2}{|c|}{ Saccharification } & \multicolumn{2}{|c|}{ Fermentation 1} & \multicolumn{2}{|c|}{ Fermentation 2} & \multicolumn{2}{|c|}{ Esterification } & \multicolumn{2}{|c|}{ Hydrogenation } & \multirow{2}{*}{$\begin{array}{l}\text { Heat and } \\
\text { power } \\
\text { Input }\end{array}$} & \multirow[t]{2}{*}{ Product } \\
\hline & Input & Output & Input & Output & Input & Output & Input & Output & Input & Output & Input & Output & Input & Output & & \\
\hline Cellulose & 10.05 & 10.05 & 10.05 & 9.25 & 9.25 & 1.22 & 7.89 & 1.22 & 1.22 & 1.22 & 1.22 & 1.22 & 1.22 & 1.22 & 1.22 & \\
\hline Xylan & 4.49 & 4.49 & 4.49 & 0.22 & 0.22 & 0.22 & 0.19 & 0.22 & 0.22 & 0.22 & 0.22 & 0.22 & 0.22 & 0.22 & 0.22 & \\
\hline Arabinan & 0.19 & 0.19 & 0.01 & 0.01 & 0.01 & 0.01 & 0.01 & 0.01 & 0.01 & 0.01 & 0.01 & 0.01 & 0.01 & 0.01 & 0.01 & \\
\hline Mannan & 0.93 & 0.93 & 0.93 & 0.01 & 0.01 & 0.01 & 0.01 & 0.05 & 0.05 & 0.05 & 0.05 & 0.05 & 0.05 & 0.05 & 0.05 & \\
\hline Galactan & 0.06 & 0.06 & & & & & & & & & & & & & & \\
\hline Acetate & 1.09 & 1.09 & 1.09 & & & & & & & & & & & & & \\
\hline Lignin & 6.52 & 6.52 & 6.52 & 6.52 & 6.52 & 6.52 & 6.52 & 6.52 & 6.52 & 6.52 & 6.52 & 6.52 & 6.52 & 6.52 & 6.52 & \\
\hline Sulfuric acid & & & 0.52 & & & & & & & & & & & & & \\
\hline $\mathrm{Ca}(\mathrm{OH})_{2}$ & & & 1.07 & & & & & & & & & & & & & \\
\hline Gypsum & & & & 0.91 & & & & & & & & & & & & \\
\hline $\mathrm{Ca}(\mathrm{Ac})_{2}$ & & & & 1.44 & & & & & 1.44 & 12.78 & 12.78 & 0.26 & & & & \\
\hline Glucose & & & & 0.73 & 0.73 & 9.90 & 9.90 & 0.91 & 0.91 & 0.91 & 0.91 & 0.91 & 0.91 & 0.91 & 0.91 & \\
\hline Glucose olig & & & & 0.09 & 0.09 & 0.09 & 0.09 & 0.09 & 0.09 & 0.09 & 0.09 & 0.09 & 0.09 & 0.09 & 0.09 & \\
\hline Cellobiose & & & & 0.07 & 0.07 & 0.07 & 0.07 & 0.07 & 0.07 & 0.07 & 0.07 & 0.07 & 0.07 & 0.07 & 0.07 & \\
\hline Xylose & & & & 3.82 & 3.82 & 3.82 & 3.26 & 0.38 & 0.38 & 0.38 & 0.38 & 0.38 & 0.38 & 0.38 & 0.38 & \\
\hline Xylose olig & & & & 0.29 & 0.29 & 0.29 & 0.29 & 0.29 & 0.29 & 0.29 & 0.29 & 0.29 & 0.29 & 0.29 & 0.29 & \\
\hline Mannose & & & & 0.77 & 0.77 & 0.77 & 0.77 & 0.77 & 0.77 & 0.77 & 0.77 & 0.77 & 0.77 & 0.77 & 0.77 & \\
\hline Arabinose & & & & 0.16 & 0.16 & 0.16 & 0.16 & 0.16 & 0.16 & 0.16 & 0.16 & 0.16 & 0.16 & 0.16 & 0.16 & \\
\hline $\begin{array}{l}\text { Arabinose- } \\
\quad \text { olig }\end{array}$ & & & & 0.01 & 0.01 & 0.01 & 0.01 & 0.01 & 0.01 & 0.01 & 0.01 & 0.01 & 0.01 & 0.01 & 0.01 & \\
\hline Tar & & & & 0.98 & 0.98 & 0.98 & 0.98 & 0.98 & 0.98 & 0.98 & 0.98 & 0.98 & 0.98 & 0.98 & 0.98 & \\
\hline Enzymes & & & & & 1.85 & 1.85 & & & & & & & & & & \\
\hline Lactic acid & & & & & & & & 10.10 & 10.10 & 1.52 & & & & & & \\
\hline Protein & & & & & & & & 1.37 & & & & & & & & \\
\hline $\mathrm{CO}_{2}$ & & & & & & & & & & & 4.68 & & & & & \\
\hline $\mathrm{CaCO}_{3}$ & & & & & & & & & 7.65 & & & 7.65 & & & & \\
\hline Ethanol & & & & & & & & & & & 6.90 & & & 12.91 & & 6.01 \\
\hline EtAc & & & & & & & & & & & & 12.61 & & & & \\
\hline $\mathrm{CH} 4$ & & & & & & & & & & & & & 1.12 & & & \\
\hline
\end{tabular}

tonnes of wet chip per hour converting into 21.6 metric tonnes of ethanol per hour, where the composition of the wood chip is cellulose: $22.2 \%$, xylan: $9.9 \%$, arabinan: $0.4 \%$, mannan: $2 \%$, galactan: $0.1 \%$, acetate: $2.4 \%$, lignin: $14.4 \%$, ash: $0.5 \%$, and moisture: $47.9 \%$ (Wooley et al., 1999). Table 1 presents a simplified mass flow of the main streams of the ethanol production process. Input water and waste water streams carrying nutrients and insoluble residues are not shown explicitly in the table but exergy losses from these streams have been taken into account in the analysis. In the following subsections we discuss various process units in more detail.

\subsubsection{Pretreatment and detoxification}

The pretreatment process adopted here is the same as reported by Wooley et al. (1999). In the pretreatment process most of the hemicellulose portion of the feedstock is converted to soluble sugars, primarily xylose, mannose, arabinose, and galactose. A small portion of the cellulose is converted into glucose. The pretreatment is carried out at $192{ }^{\circ} \mathrm{C}$ in (13 bar) steam with $0.5 \%$ sulphuric acid for $10 \mathrm{~min}$ at a consistency of $22 \%$. Detailed information including the soluble sugars yields from hemicellulose and cellulose is available in Wooley et al. (1999).

After the pretreatment process, the detoxification is carried out in two stages. First the sulphuric acid $\left(\mathrm{H}_{2} \mathrm{SO}_{4}\right)$ is neutralised by reacting with $\mathrm{Ca}(\mathrm{OH})_{2}$ to produce gypsum $\left(\mathrm{CaSO}_{4} \cdot 2 \mathrm{H}_{2} \mathrm{O}\right)$. The gypsum is then removed and the stream is carried to the second stage. In the second stage in our model, the acetic acid $\left(\mathrm{CH}_{3} \mathrm{COOH}\right)$ is reacted with $\mathrm{Ca}(\mathrm{OH})_{2}$ to produce calcium acetate, $\mathrm{Ca}(\mathrm{Ac})_{2}$ which is separated and taken to the esterification process. This process differs from Wooley et al. (1999) where $\mathrm{Ca}(\mathrm{Ac})_{2}$ is considered as waste.

\subsubsection{Saccharification}

In this process cellulose is hydrolysed by a combination of three enzymes: endo-b-glucanase, exo-glucanase and b-glucanase. We have assumed $81.2 \%$ glucose yield from cellulose by the enzymatic saccharification process (Wyman et al., 2009). The saccharification is carried out at $5 \%$ consistency with $48 \mathrm{~h}$ residence time. In the HYBC process, enzymes are not produced on site, so electricity intensive agitator for the enzyme seed production can be avoided. Wooley et al. (1999) have suggested electricity requirements for a continuously stirred tank reactor (CSTR) of: $20 \mathrm{~W} / \mathrm{m}^{3}$ for low viscosity solution and $60 \mathrm{~W} / \mathrm{m}^{3}$ for high viscosity solution. We have used CSTR electricity requirements of $30 \mathrm{~W} / \mathrm{m}^{3}$ for our calculation. We also assume reactors are operated in sequence for the saccharification stage to obtain a semi-continuous process (Wooley et al., 1999). Four such sequences are used in the saccharification stage. The saccharification stage was assumed to have no process heat requirements.

\subsubsection{Fermentation}

Fermentation is carried out in two stages. In stage one fermentable sugars are converted into lactic acid and single cell protein. This stage uses a homofermentative lactic acid bacteria (Verser and Eggman, 2003). In the second stage lactic acid is converted into acetic acid by homofermentative acetogenic bacteria such as Lactobacillus casei (Verser and Eggman, 2003).

The feed to the fermentation is very dilute in carbohydrates with only about $5 \%$ fermentable sugars. The low carbohydrate concentration in the feed will limit the effects of product inhibition on the cell growth and acid production kinetics (Verser and Eggman, 2003). We have assumed $90 \%$ conversion of the sugars. Single cell proteins are produced as the by-product of first stage fermentation. These proteins can be used as animal feed and are considered as a useful product in the exergy analysis.

Second stage fermentation is carried out using homofermentative acetogens. Homofermentative acetogens are sensitive to low $\mathrm{pH}$ and product inhibition occurs at much lower concentrations than lactic acid bacteria. Optimal $\mathrm{pH}$ is around 7 and maximum acetate tolerance is only about $30 \mathrm{~g} / \mathrm{l}$ ( $3 \%$ consistency) in batch fermentation. The $\mathrm{pH}$ is controlled by adding $\mathrm{CaCO}_{3}$ which produces 
calcium acetate $\left(\mathrm{Ca}(\mathrm{Ac})_{2}\right)$ and $\mathrm{CO}_{2}$ by reacting with acetic acid. However, acetate salts are also an inhibitor to acetic acid production and, therefore second stage fermentation must be carried out at even lower concentration (Verser and Eggman, 2003). We have assumed $5 \%$ consistency for our calculations. The acetic acid yield from lactic acid is assumed to be $85 \%$.

Both fermentation stages are carried out in continuous stirred tank reactors (Wooley et al., 1999) with residence time of $24 \mathrm{~h}$. In NREL's earlier publication (Wooley et al., 1999) fermentation agitator power requirement was assumed to be 20 to $60 \mathrm{w} / \mathrm{m}^{3}$, in a recent publication (Humbird et al., 2011) this value has been reduced to $6 \mathrm{~W} / \mathrm{m}^{3}$ with the assumption that most of the liquefaction and viscosity reduction take place in the continuous high-solid hydrolysis process. De La Roza et al. (2002) have presented experimental values for fermentation agitator power requirements. For $1060 \mathrm{~g} / \mathrm{l}$ density solution they (De La Roza et al., 2002) have found agitator power requirement to be $39.6 \mathrm{~W} / \mathrm{m}^{3}$. In the HYBC process, fermentation is carried out at $5 \%(\mathrm{w} / \mathrm{w})$ consistency which is very close to the solution density of De La Roza et al. (2002). So we have used an electricity requirement of $40 \mathrm{~W} / \mathrm{m}^{3}$ for the fermentation stage. We assumed that the reactors of both fermentation stages are arranged as sequences to obtain a semi-continuous process. Two such sequences are used for each fermentation stage. We have also assumed that no process heat is required in the fermentation process.

\subsubsection{Esterification}

Esterification was achieved assuming a reactive distillation process. In the reactive distillation process, a dilute solution (5\%) of calcium acetate $\left(\mathrm{Ca}(\mathrm{Ac})_{2}\right)$ in water is mixed with ethanol and fed to the top of the reactive distillation column. Carbon dioxide is fed to the column from the bottom section. The simultaneous reaction of $\mathrm{CO}_{2}$ with $\mathrm{Ca}(\mathrm{Ac})_{2}$ and ethanol produces $\mathrm{CaCO}_{3}$ and ethyl acetate (EtAc). This process recovers the acetic acid from the dilute salt solution producing a relatively concentrated product stream at the top of the reactive column without vaporising the water that forms the bulk of the stream thereby reducing the energy requirement. Eqs. (3)-(5) summarises the chemical reactions occurring in the distillation column.

$\mathrm{CO}_{2}(\mathrm{~g})+\mathrm{H}_{2} \mathrm{O} \rightarrow \mathrm{H}_{2} \mathrm{CO}_{3}$

$\mathrm{Ca}(\mathrm{Ac})_{2}+\mathrm{H}_{2} \mathrm{CO}_{3} \rightarrow \mathrm{CaCO}_{3}(\mathrm{~s})+2 \mathrm{HAc}$

$2 \mathrm{HAc}+2 \mathrm{EtOH} \rightarrow 2 \mathrm{EtAc}$

The most volatile component in the reaction mixture is the ethyl acetate/water/ethanol azeotrope. Azeotrope is a mixture of two or more liquid components that cannot be separated by simple distillation as the mixture has a distinct boiling point. The azeotrope composition is $82.6 \%$ ethyl acetate, $9 \%$ water and $8.4 \%$ ethanol. The azeotrope boils at $70.2^{\circ} \mathrm{C}$. The azeotrope is removed from the reaction mixture by vaporisation along with some ethanol and water. The bottom product is a solution of ethanol and water containing the suspended $\mathrm{CaCO}_{3}$. The azeotrope can be broken down by adding water, which causes a phase separation, with the water and ethanol rich phase returned to the appropriate point in the reactive distillation column. The $\mathrm{CaCO}_{3}$ is recovered and used in the fermentation stage.

\subsubsection{Hydrogenation}

The ester of acetic acid is converted into two alcohols by hydrogenation (see Eq. (6)). The reaction is performed at $250^{\circ} \mathrm{C}$ and 206 bar in the liquid phase. Copper chromite is used as the catalyst for the reaction. The hydrogenation process is a highly exothermic. The excess heat is recovered and used for the internal heat demands at various stages of the bioethanol production.

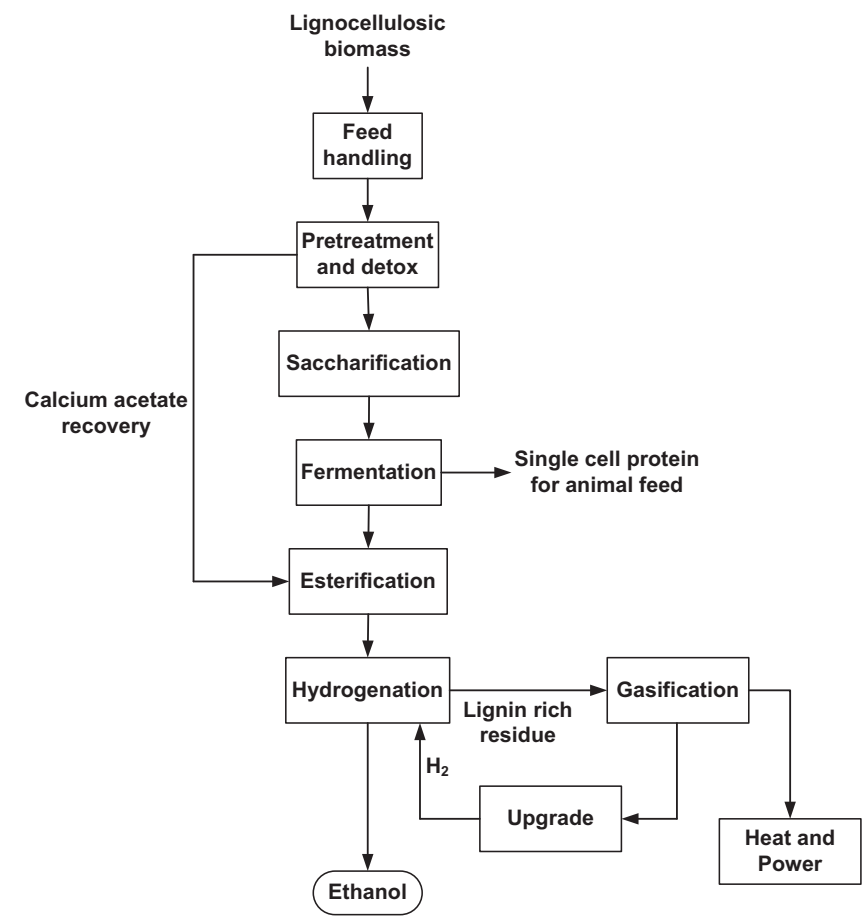

Fig. 2. Simplified schematic process flow for an alternative HYBC process where hydrogen is produced from gasifying the lignin-rich residue.

$\mathrm{EtAc}+2 \mathrm{H}_{2} \rightarrow 2 \mathrm{EtOH}$

\subsubsection{Hydogen production and heat and power production}

The required hydrogen for the hydrogenation process can be produced from steam reforming methane (natural gas). Here, our calculations were limited to input and output quantities (system level) of the reforming process. Eqs. (7) and (8) summarises the steam reforming reactions.

$\mathrm{CH}_{4}+\mathrm{H}_{2} \mathrm{O} \rightarrow \mathrm{CO}+3 \mathrm{H}_{2}$

$\mathrm{CO}+\mathrm{H}_{2} \mathrm{O} \rightarrow \mathrm{CO}_{2}+\mathrm{H}_{2}$

The lignin and other residues are combusted in a suitable boiler to produce heat and power. The heat and power unit is modelled assuming 23\% (exergetic) efficient (Wooley et al., 1999) as base the case. This value of efficiency is on the conservative side. Henderick and Williams (2000) have used a thermal efficiency of heat and power production of $21-34 \%$. Based on a typical combustion temperature of lignin the Carnot efficiency is about 72\% (Sohel and Jack, 2010). We consider a range of $30-50 \%$ for exergetic efficiency of the heat and power producing unit.

It is also possible to meet the required hydrogen demand by gasifying the lignin-rich residue and still be self-sufficient in energy. Fig. 2 shows a simplified schematic process flow for an alternative version of the process for ethanol production from wood chip where hydrogen is produced from lignin-rich residue. In this case, the heat and power for the process can also be met internally. For our calculations we have assumed supercritical water gasification for hydrogen production and used data presented by Lu et al. (2007).

\subsection{Exergy analysis}

Exergy analysis provides a straight-forward method of analysing the thermodynamic efficiency of a process and identifying thermodynamic inefficiencies (Szargut et al. (1988)). Lu et al. (2007) 
and Prins et al. (2005) have discussed the general approach to applying exergy analysis to biofuel production processes. In our previous work (Sohel and Jack, 2011), we have discussed aspects of exergy analysis relevant to biochemical processes.

The thermodynamic efficiency of a system is defined as (Szargut et al., 1988):

$\eta=\frac{\text { Exergy of useful products }}{\text { Input exergy }}$

In the current case, the overall efficiency of ethanol production via the HYBC process described above can be written as:

$\eta=\frac{E_{\mathrm{X}, \text { Fuel }}+\sum_{\text {out }} E_{\mathrm{X}, \text { prd }}}{E_{\mathrm{X}, \text { Biomass }}+\sum_{\mathrm{in}} E_{\mathrm{X}}}$

where, $E_{\mathrm{X}, \text { Biomass }}$ is the input exergy in biomass, $\sum_{\mathrm{in}} E_{\mathrm{X}}$ is the total input exergy of chemical components, $E_{\mathrm{X}, \text { Fuel }}$ is the exergy in fuel and $\sum_{\text {out }} E_{\mathrm{X} \text {,prd }}$ is the total exergy in the useful products.

The exergy balance (Dincer and Rosen, 2007) applied to the system boundary of a unit operation of a process gives:

$\sum_{\text {in }} E_{\mathrm{X}}=\sum_{\text {out }} E_{\mathrm{X}, \mathrm{prd}}+\sum_{\text {out }} E_{\mathrm{X}, \text { wstprd }}+I$

where $\sum_{\mathrm{in}} E_{\mathrm{X}}$ is the total input exergy flow, $\sum_{\text {out }} E_{\mathrm{X}, \text { prd }}$ is the total output exergy flow of the products, $\sum_{\text {out }} E_{X \text {.wstprd }}$ is the total output exergy flow of the waste products and $I$ is the exergy lost due to internal irreversibility for the unit process considered.

\subsection{Yield}

In biofuel production processes, yield (see Eq. (12)) can be defined as the ratio between the quantity of biofuel produced and biomass consumed.
$Y=\frac{\text { mass of biofuel }}{\text { mass of biomass }}$

In the thermochemical pathway to biofuel production (gasification followed by Fischer-Tropsch synthesis (Prins et al., 2005)), theoretically all of the components of biomass can be converted to biofuel. However, in the biochemical pathway to biofuel production, only the cellulose and hemicellulose parts of the biomass can be converted into biofuel (ethanol). In this case biofuel yield from a $\mathrm{kg}$ of biomass can be defined by:

$Y=\alpha \cdot \beta$

where, $\alpha=\frac{\text { mass of cellulose and hemicellulose }}{\text { mass of biomass }}$ $\beta=\frac{\text { mass of biofuel }}{\text { mass of cellulose and hemicellulose }}$.

and

\section{Results and discussion}

\subsection{Exergy analysis of the HYBC process}

A Grassman diagram showing the flow of exergy in the bioethanol production process is presented in Fig. 3. This diagram is based on the HYBC process, where the required hydrogen is supplied from steam reforming of natural gas. The Grassman diagram presents overall exergy balances as well as input-output exergies in all major unit operations. The overall efficiency of the hybrid process is calculated to be $38 \%$, using Eq. (10), where total chemical exergy in biomass is $E_{\mathrm{X}, \text { Biomass }}=451.7 \mathrm{MW}$, the total exergy input in the consumables is $\sum_{\text {in }} E_{\mathrm{X}}=97.7 \mathrm{MW}$, the exergy output as fuel is $E_{\mathrm{X} \text {.Fuel }}=160 \mathrm{MW}$ and the total useful exergy in the by-products (including electricity) is $\sum_{\text {out }} E_{\mathrm{X}, \mathrm{prd}}=48.7 \mathrm{MW}$. The losses in various unit operations for the HYBC process are: feed handling $0.3 \%$ (1 MW), pretreatment and detoxification 7.7\% (26.2 MW),

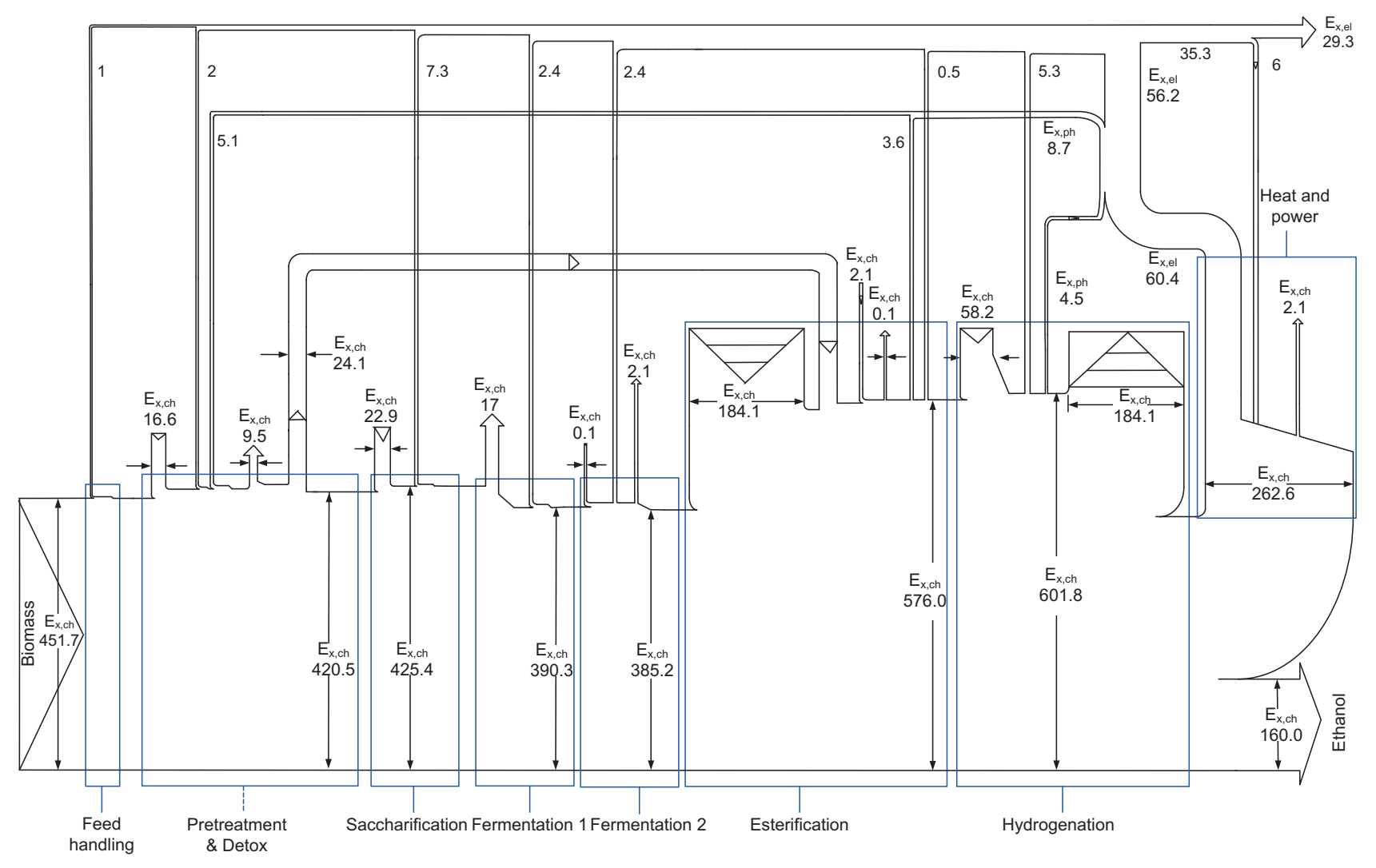

Fig. 3. Grassman diagram for the HYBC process for ethanol production from wood chip (all units are in MW). 
saccharification 7.5\% (25.6 MW), fermentation 8.2\% (27.7 MW), esterification $6.9 \%$ (23.5 MW), hydrogenation 9.8\% (33.3 MW) and heat \& power 59.6\% (202.2 MW). The losses in the HYBC process with gasification are: feed handling $0.3 \%(1 \mathrm{MW})$, pretreatment and detoxification $8.9 \%$ (26.2 MW), saccharification $8.7 \%$ (25.6 MW), fermentation 9.5\% (27.7 MW), esterification $8.0 \%$ (23.5 MW), gasification $8.4 \%$ (24.6 MW), hydrogenation $13.9 \%$ (40.9 MW) and heat \& power 42.3\% (202.2 MW).

\subsection{Yield versus thermodynamic efficiency}

As discussed in the introduction, the theoretical yield of ethanol from the conventional biochemical process and the HYBC process are $\beta=52 \%$ and $\beta=77 \%$, respectively. With $\alpha=71.3 \%$ (dry basis) cellulose and hemicellulose (Wooley et al., 1999) in the feedstock, the theoretical yields per unit of input biomass of the biochemical and HYBC processes become $Y=37.1 \%$ and $Y=54.9 \%$, respectively using Eq. (13).

Prins et al. (2005) have used wood sawdust as the feedstock for a thermochemical pathway to biofuel production. The sawdust is dried to $10 \mathrm{wt} . \%$ moisture by indirect drying using reaction heat from the Fischer-Tropsch (FT) synthesis. It is then autothermally gasified with air at a temperature of $900{ }^{\circ} \mathrm{C}$ and atmospheric pressure. The gas is cooled and subsequently cleaned. Ash particles are separated by filtration and acid gases, ammonia and salts are washed by water from the synthesis gas. The gas is compressed and catalytically shifted in a suitable reactor and then fed in a FT reactor. The overall chemical formula of sawdust can be represented as $\mathrm{CH}_{1.35} \mathrm{O}_{0.617}$ (Lu et al., 2007). From Prins and co-worker's (2005) all the processes can be summarised by,

$$
\begin{aligned}
\mathrm{CH}_{1.35} \mathrm{O}_{0.617}+0.192 \mathrm{O}_{2} \rightarrow & {[-\mathrm{CH} 2-]_{0.558}+0.442 \mathrm{CO}_{2} } \\
& +0.117 \mathrm{H}_{2} \mathrm{O}
\end{aligned}
$$

The theoretical biofuel yield for the thermochemical pathway is calculated to be $33.6 \%$ (w/w) from Eq. (14).

We also consider the normalised yield which is defined as the ratio between actual yield and the theoretical yield:

$x=\frac{Y_{\text {actual }}}{Y_{\text {theoretical }}}$

Normalised yield provides a measure of the state of development of a technology in terms of its yield. Fig. 4 presents the yield, the normalised yield and the overall thermodynamic efficiencies of

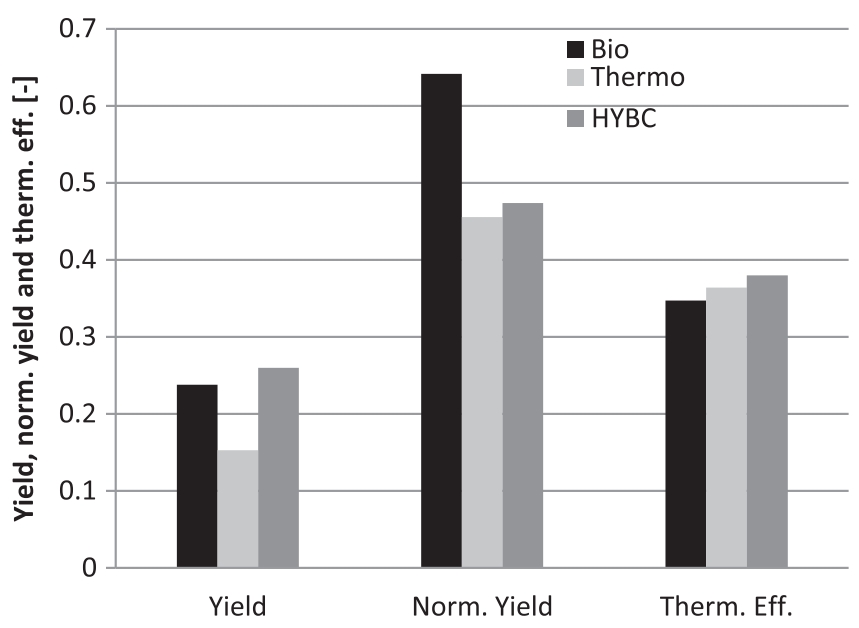

Fig. 4. Comparison of yield, normalised yield, and overall thermodynamic (exergy) efficiencies of the thermochemical (thermo), biochemical (Bio) and the HYBC processes.
Table 2

Comparison of exergy losses (\% of total loss) in the thermochemical, biochemical and

\begin{tabular}{|c|c|c|c|c|}
\hline Process unit & $\begin{array}{l}\text { Losses in } \\
\text { thermochemical } \\
\text { process (Prins } \\
\text { et al., 2005) [\%] }\end{array}$ & $\begin{array}{l}\text { Losses in } \\
\text { biochemical } \\
\text { process (Sohel } \\
\text { and Jack, 2011) } \\
\text { [\%] }\end{array}$ & $\begin{array}{l}\text { Losses } \\
\text { in HYBC } \\
\text { process } \\
{[\%]}\end{array}$ & $\begin{array}{l}\text { Losses in } \\
\text { HYBC } \\
\text { process } \\
\text { with } \\
\text { gasification } \\
\text { [\%] }\end{array}$ \\
\hline Biomass drying & 4.3 & & & \\
\hline Feed handling & & 0.4 & 0.3 & 0.3 \\
\hline Pretreatment + detox & & 2.5 & 7.7 & 8.9 \\
\hline Biomass gasification & 34.2 & & & 8.4 \\
\hline Saccharification & & & 7.5 & 8.7 \\
\hline SSCF seed & & 10.8 & & \\
\hline SSCF process & & 15.9 & & \\
\hline Fermentation & & & 8.2 & 9.5 \\
\hline Syngas cleaning & 0.6 & & & \\
\hline Syngas compression & 4.8 & & & \\
\hline WGS reactors & 0.8 & & & \\
\hline $\begin{array}{l}\text { Distillation \& } \\
\text { dehydration }\end{array}$ & & 1.1 & & \\
\hline Evaporation & & 1.3 & & \\
\hline $\begin{array}{l}\text { Biofuel synthesis } \\
\text { reactor }\end{array}$ & 2.9 & & & \\
\hline Biofuel separation & 2.0 & & & \\
\hline Esterification & & & 6.9 & 8.0 \\
\hline Hydrogenation & & & 9.8 & 13.9 \\
\hline Lignin separation & & 0.7 & & \\
\hline Heat recovery & 14.2 & & & \\
\hline Power generation & 36.2 & 67.3 & 59.6 & 42.3 \\
\hline
\end{tabular}
HYBC processes.

the biochemical (Sohel and Jack, 2011), thermochemical (Prins et al., 2005), and HYBC processes. In Fig. 4 the biochemical pathway to biofuel has the highest normalised yield indicating that the biochemical pathway to biofuel has less room for improvement in yield. The thermochemical pathway to biofuel has the lowest normalised yield so the potential for yield improvement is the highest.

The overall thermodynamic efficiencies of these three processes are of a similar range with the biochemical pathway to biofuel having the lowest and the HYBC process having the highest. A clear correlation between yield, normalised yield, and thermodynamic efficiency is not evident from Fig. 4 which is contrary to the current emphasis in some of the literatures (Lavarack et al., 2007) on yield. We conclude from this that it is necessary to consider both yield and thermodynamic efficiency as evaluation metrics for biofuel production processes. Note that current analysis is based only on yield and thermodynamic efficiency. Techno-economic analysis (Galbe et al., 2007; Gnansounou and Dauriat, 2010) may highlight different aspects of these biofuel production processes. However such a study is beyond the scope of this paper.

Table 2 presents a comparison of exergy losses in the thermochemical, biochemical, HYBC and HYBC with lignin gasification processes. The heat and power production step has the largest exergy loss. In our previous work (Sohel and Jack, 2011), we have discussed the fact that lignin has a much higher chemical exergy than the cellulose and hemicellulose fractions of the biomass, so that the efficiency of the biochemical process largely depends on how lignin is utilised. This is indeed true for the HYBC process. If we increase the efficiency of the heat and power production unit to $50 \%$, the overall efficiency of the HYBC process becomes 50\%, a significant improvement from $38 \%$. Thus, to improve the efficiency of the biofuel production process we have to produce consumable renewable products from the lignin or convert as much as lignin as possible into biofuel (gasification of lignin to provide hydrogen for the HYBC process is discussed further below). In this way, much of the chemical exergy of lignin will be retained. This is very much in line with the "integrated biorefinery" concept (Demirbas, 2009; Ragauskas 
et al., 2006) where a range of high-value co-products are produced in addition to commodity fuel products. Future research focusing on "integrated biorefinery" concepts would be a useful step towards achieving more efficient conversion processes.

The second largest contributor to exergy loss in the HYBC process is the hydrogenation process. This process uses hydrogen, which has a very high chemical exergy, as a consumable making the hydrogenation process inherently inefficient. In our analysis for the base case, we have assumed that hydrogen demand is met from methane, another substance with a high chemical exergy. If we meet the hydrogen demand of the HYBC by gasifying the lignin-rich residue the overall efficiency of the process does not change significantly (see Fig. 2). This is somewhat surprising result is mainly due to the fact that much of the exergy in the lignin-rich residue is lost in the gasification process required for the hydrogen production. For our calculations we have assumed supercritical water gasification for hydrogen production (Lu et al., 2007).

The third largest contributor to the exergy loss is the fermentation (fermentation 1 and 2 combined) process. In the fermentation process majority of the loss is due to the internal irreversibility.

The fourth largest contribution to the exergy loss is the pretreatment and detoxification process. This process is very similar to the pretreatment and detoxification process of biochemical pathway (Sohel and Jack, 2011) except that in the HYBC process no ammonia was used.

The saccharification process is responsible for the fifth largest exergy loss $(7.6 \%)$ in the HYBC process. This loss is much less than the $26.7 \%$ exergy loss in the simultaneous saccharification and co fermentation (SSCF) process step of the biochemical process (Sohel and Jack, 2011). In the biochemical process the SSCF process step was completed at about $22 \%$ consistency (solid content) whereas the current HYBC process has a limit for solid content in the solution of about $5 \%$ as beyond this level the solids act as an inhibitor. Such dilute conditions are responsible for less viscous loss in the saccharification reactors (Wooley et al., 1999) and consequently less overall exergy loss in the saccharification process of the HYBC process.

The sixth largest contributor to exergy losses are different for HYBC and HYBC with gasification. For HYBC the esterification process is the sixth largest contributor to exergy loss. Esterification was achieved using a reactive distillation process. This process plays a similar role to the evaporation and distillation process steps of the biochemical pathway. The reactive distillation process is found to be more efficient than the conventional evaporation and distillation process (Wooley et al., 1999). In the reactive distillation process less heat is required. Ethyl acetate/ water/ethanol azeotrope is produced in the reactive distillation process. The azeotrope can be broken by adding water. The ethyl acetate layer separates from the water easily so an energy intensive distillation process is avoided. For HYBC with gasification, the gasification represents the sixth largest contributor to the exergy loss. In the gasification process a large amount of entropy is generated due to the high working temperature and leads to a large loss.

\section{Conclusion}

The high-yield biochemical process considered here has similar order of thermodynamic efficiency to other processes. It's efficiency can be increased significantly by improving the heat and power production process. The hydrogenation process was found to be inherently inefficient due to the large exergy input from hydrogen. This is true, regardless of whether the hydrogen is produced from steam reforming of methane or by gasifying the lignin-rich residue. A survey of a number of different biofuel production process found no direct correlation between yield and thermodynamic efficiency, demonstrating that yield alone can be an unreliable performance metric.

\section{References}

Demirbas, A., 2009. Biorefineries: current activities and future developments. Energy Convers. Manage. 50 (11), 2782-2801.

De La Roza, C., Laca, A., García, L.A., Díaz, M., 2002. Stirring and mixing effects at different cider fermentation scales. Food Bioprod. Process. 80, 129-134.

Dincer, I., Rosen, M.A., 2007. Exergy: Energy, Environment and Sustainable Development. Elsevier.

Galbe, M., Sassner, P., Wingren, A., Zacchi, G., 2007. Process engineering economics of bioethanol production. Adv. Biochem. Eng. Biotechnol. 108, 303-327.

Gnansounou, E., Dauriat, A., 2010. Techno-economic analysis of lignocellulosic ethanol: a review. Bioresour. Technol. 101, 4980-4991.

Granda, C.B., Holtzapple, M.T., Luce, G., Searcy, K., Mamrosh, D.L., 2009. Carboxylate platform: the mixalco process part 2: process economics. Appl. Biochem. Biotechnol. 156, 537-554.

Henderick, P., Williams, R.H., 2000. Trigeneration in a Northern Chinese village using crop residues. Energy Sustain. Dev. 4 (3), 26-42.

Holtzapple, M.T., Davison, R.R., Ross, M.K., Aldrett-Lee, S., Murlidhar Nagwani, C.-M. Lee, C., Lee, S., Adelson, W., Kaar, D., Gaskin, H., Shirage, N.-S., Chang V.S.Chang, Loescher, M.E., 1999. Biomass conversion to mixed alcohol fuels using the MixAlco process. Appl. Biochem. Biotechnol. 79, 609-631.

Huber, G.W., Iborra, S., Corma, A., 2006. Synthesis of transportiation fuels from biomass: chemistry, catalysis, and engineering. Chem. Rev. 106, 4044-4098.

Humbird, D., Davis, R., Tao, L., Kinchin, C., Hsu, D., Aden, A., Schoen, P., Lukas, J. Olthof, B., Worley, M., Sexton, D., Dudgeon, D., 2011. Process Design and Economics for Biochemical Conversion of Lignocellulosic Biomass to Ethanol. National Renewable Energy Laboratory (NREL).

Lavarack, B.P., Eggeman, T., Edye, L.A., Hobson, P.A., Blinco, J.L., Bullock, G.E., 2007. An update of the ZeaChem process for increased ethanol production. Int. Sugar J. 109 (1307), 679-683.

Lu, Y., Guo, L., Zhang, X., Yan, Q., 2007. Thermodynamic modeling and analysis of biomass gasification for hydrogen production in supercritical water. Chem. Eng. J. 131 (1-3), 233-244.

Piccolo, C., Bezzo, F., 2009. A techno-economic comparison between two technologies for bioethanol production from lignocellulose. Biomass Bioenergy 33 (3), 478-491.

Prins, M.J., Ptasinski, K.J., Janssen, F.J.J.G., 2005. Exergetic optimisation of a production process of Fischer-Tropsch fuels from biomass. Fuel Processing Technol. 86 (4), 375-389.

Ragauskas, A.J., Williams, C.K., Davison, B.H., Britovsek, G., Cairney, J., Echert, C.A., Frederick Jr., W.J., Hallett, J.P., Leak, D.J., Liotta, C.L., Mielenz, J.R., Murphy, R., Templer, R., Tschaplinski, T., 2006. The path forward for biofuels and biomaterials. Science 311, 484-489.

Sohel, M.I., Jack, M., 2010. Efficiency improvements by geothermal heat integration in a lignocellulosic biorefinery. Bioresour. Technol. 101, 9342-9347.

Sohel, M.I., Jack, M.W., 2011. Thermodynamic analysis of lignocellulosic biofuel production via a biochemical process: guiding technology selection and research focus. Bioresour. Technol. 102, 2617-2622.

Szargut, J., Morris, D.R., Steward, F.R., 1988. Exergy Analysis of Thermal, Chemical, and Metallurgical Processes. Hemisphere Publishing Corporation.

Verser, D., Eggman, T. 2003. Process for producing ethanol. U.S. Patent, Golden, CO (US).

Wooley, R., Ruth, M., Sheehan, J., Ibsen, K., Majdeski, H., Galvez, A., 1999. Lignocellulosic Biomass to Ethanol Process Design and Economics Utilizing Co-Current Dilute Acid Prehydrolysis and Enzymatic Hydrolysis Current and Futuristic Scenarios. National Renewable Energy Laboratory (NREL).

Wyman, C.E., Dale, B.E., Elander, R.T., Holtzapple, M., Ladisch, M.R., Lee, Y.Y Mitchinson, C., Saddler, J.N., 2009. Comparative sugar recovery and fermentation data following pretreatment of poplar wood by leading technologies. AIChE Biotechnol. Prog. 25, 333-339. 